\title{
ESTUDO DA POSSIBILIDADE DE APLICAÇÃO INDUSTRIAL DE UM PROCESSO INOVADOR DE REFINAÇÃO DE AZEITE
}

\author{
Paulo Almeida Pereira*
}

\begin{abstract}
$O$ azeite é um produto com larga utilização, principalmente na culinária, fazendo parte da cultura mediterrânica e, nomeadamente, da portuguesa. Neste trabalho caracteriza-se o processo que vai desde a cultura da oliveira até à produção do azeite e analisa-se o mercado de produção de azeite, a nível nacional, sendo feita a desagregação, essencialmente, por tipo de azeite virgem (no que diz respeito à sua qualidade) e por regiões.

A extracção supercrítica é um processo inovador que permite a extracção, através de um método "ecológico", de componentes a partir de produtos naturais, aplicável à refinação de azeite. Um estudo de "scale-up" (dimensionamento) de uma unidade industrial para este processo de refinação, acompanhado por um estudo de viabilidade económica, permite chegar à conclusão de que este processo é, numa primeira análise, viável.
\end{abstract}

\section{INTRODUÇÃO HISTÓRICA}

O termo azeite, etimologicamente, tem origem árabe, derivando do termo az-zait (Costa e Melo, 1992), significando óleo extraído da azeitona. $\mathrm{Na}$ Bíblia Sagrada, encontram-se várias referências à oliveira: a Terra Prometida é designada por País das Oliveiras, a narração da preparação da Paixão por

Instituto Universitário de Desenvolvimento e Promoção Social - Pólo de Viseu do Centro Regional das Beiras da Universidade Católica Portuguesa. 
Cristo ocorre no Monte das Oliveiras e os seus seguidores saúdam a chegada do Mestre à cidade de Jerusalém, agitando ramos de Oliveira.

O azeite é um dos mais antigos produtos naturais. Ao longo dos tempos, foi utilizado na iluminação (desde as candeias aos candelabros de templos e palácios), como óleo sagrado nos altares (para ofícios litúrgicos, baptismo e até na passagem para a morte) e na medicina (como unguento para aliviar a dor). No entanto, as utilizações quotidianas prendem-se cada vez mais exclusivamente com a culinária.

Embora os romanos já tenham possivelmente encontrado a cultura da oliveira na Península Ibérica, terá sido com a romanização que esta, tal como outras (por exemplo, o trigo), experimentou um significativo incremento em Portugal (Fernandez, 1983). Os árabes mantiveram a cultura da oliveira e fizeram-na prosperar, assumindo um papel fundamental na economia da produção agrícola, que se prolongou ao longo da Idade Média: no século XIII e ao longo dos séculos seguintes, o azeite é um produto que ocupa um lugar relevante nas exportações portuguesas para outros países europeus.

O azeite e a oliveira estão, deste modo, presentes na cultura mediterrânica e, nomeadamente, em Portugal, desde há milhares de anos. $\mathrm{O}$ clima do nosso país cimentou esta ligação, providenciando condições excelentes para o desenvolvimento da cultura da oliveira.

\section{DA CULTURA DA OLIVEIRA ATÉ AO AZEITE}

Existe um grande número de variedades de oliveira cultivadas no mundo inteiro, que dificultam a sua classificação e reconhecimento, devido à grande diversidade e riqueza do material vegetal. Esta situação pode ser atribuída à antiguidade do cultivo e às mutações que surgiram ao longo dos anos, que originou uma multiplicação das variedades de oliveira. Também os métodos utilizados, em cada região, ao longo do ciclo produtivo, apresentam disparidades que dependem da evolução própria da cultura da oliveira em cada local. Deste modo, as carácterísticas das oliveiras e do seu produto - o azeite - diferem bastante de região para região (Martí, 1993).

Para a descrição do ciclo de produção do azeite (Sada, 1993), o início dáse com o florescimento da oliveira, que origina mais tarde a azeitona. A apanha da azeitona, no final do ano, pode ser realizada pelos métodos tradicionais: ripada da árvore à mão e/ou varejada, ou utilizando métodos mecânicos, através de máquinas vibradoras que provocam a queda das azeitonas, sobre panos, de modo a aproveitar todo o fruto. 
Depois de recolhida, procede-se ao transporte da azeitona para o lagar, onde é lavada e pesada. De acordo com o seu estado de maturação e variedade, a azeitona é seleccionada para a transformação em azeite (que se apresenta límpido) e em bagaço (bastante mais escuro). Este processo envolve a trituração, originando uma massa que é de seguida decantada, para separar o azeite do bagaço. $O$ azeite é então centrifugado para uma primeira limpeza de impurezas, limpeza essa que prossegue através de um novo processo de decantação, que vai finalmente dar origem ao azeite puro, pronto a ser embalado. $\mathrm{O}$ azeite, como produto final, pode ser de vários tipos, de acordo com o grau de acidez que possui: extra (com acidez inferior a $1^{\circ}$ ), fino (acidez entre $1,1^{\circ}$ e $2^{\circ}$ ), corrente (acidez entre $2,1^{\circ}$ e $3,3^{\circ}$ ) e lampante (acidez superior a $\left.3,3^{\circ}\right)^{1}$.

O azeite, resultante do processo previamente descrito, é denominado azeite virgem, ou seja, "azeite obtido a partir do fruto da oliveira, unicamente por processos mecânicos ou outros processos físicos, em condições, nomeadamente térmicas, que não provoquem alteração do azeite e que não tenham sofrido qualquer tratamento para além da lavagem de decantação, da centrifugação e da filtragem, com exclusão dos azeites obtidos com solventes ou por processos de reesterificação e de qualquer mistura com óleos de outra natureza", de acordo com o conceito apresentado pelo Instituto Nacional de Estatística (INE - Estatísticas Agrícolas). Esta definição é bastante importante, uma vez que qualquer azeite refinado, por exemplo, através da destilação (que utiliza condições térmicas bastante elevadas), terá uma maior dificuldade de aceitação por parte do mercado, devido às alterações a que é submetido.

O azeite é o que se pode denominar por uma gordura saudável, de cor amarela (dourada ou esverdeada), cujo alto valor está na sua fraca acidez, na sua transparência, no seu perfume e no seu gosto suave e característico. A diversidade da azeitona (tipo e região), as condições de cultivo e o processo de extracção têm grande influência no sabor e na cor do azeite, originando um produto que permite a escolha de um entre vários sabores, de acordo com as preferências de cada consumidor. $O$ gosto característico do azeite dá-lhe vantagem sobre outros óleos, sem cor nem sabor.

O azeite é uma gordura considerada saudável. Esta afirmação é consolidada pelo facto de os países da orla mediterrânea registarem os menores índices de doenças cardiovasculares, sendo que é a região onde o consumo de azeite é maior. A composição do azeite é bastante equilibrada, destacando-se as presenças do ácido oleico, entre outros ácidos gordos, de terpenos, como o esqualeno e $\beta$-caroteno (vitamina A), de clorofilas, responsáveis pela coloração, de tocoferóis (vitamina $\mathrm{E}$ ), com efeitos antioxidantes, de esteróis, como o $\beta$-citoesterol, que provocam redução no teor 
de colesterol no sangue. A presença deste conjunto de substâncias desempenha um papel relevante na prevenção das doenças cardiovasculares, no crescimento e consolidação da estrutura óssea e na prevenção do envelhecimento dos tecidos (Conselho Oleícola Internacional - COI, 1985).

\section{O MERCADO DO AZEITE}

No mercado português de consumo de gorduras alimentares, o azeite ocupa um lugar importante, embora o consumo por habitante seja o menor dos países produtores (Martí, 1993). Isto deve-se às rápidas transformações socioeconómicas, que provocam alterações nos hábitos alimentares dos jovens e nos estilos de vida urbanos adoptados pelos adultos.

A produção nacional de azeite tem-se mantido aproximadamente em 2,5\% da produção mundial, sendo os maiores produtores a Espanha, Itália, Grécia, Turquia e Tunísia. A produção na bacia mediterrânica é de aproximadamente $95 \%$ do total mundial (COI, 1984).

Para efectuar uma breve análise sobre a produção nacional de azeite, com o objectivo de elucidar alguns aspectos considerados importantes para este trabalho, serão utilizados dados obtidos através do Instituto Nacional de Estatística, na sua publicação Estatísticas Agrícolas (1993 a 1997).

A produção de azeite em Portugal movimenta anualmente valores na ordem das dezenas de milhões de contos, sendo, portanto, um produto com uma dimensão comercial bastante relevante. No Quadro I apresentam-se os valores da produção nacional de azeite, a preços correntes.

Como se pode observar, desde 1993 até 1996, os valores da produção nacional de azeite têm vindo a aumentar, com excepção do ano de 1995, em que ocorreu um pequeno decréscimo relativamente ao ano anterior. É de salientar que a produção, em cada ano agrícola, é condicionada pelas condições climatéricas, podendo ocorrer grandes flutuações. $O$ aumento nos valores de produção explica-se, como se poderá verificar de seguida, por aumentos nas quantidades produzidas e pelo aumento do preço do azeite. 


\section{Quadro I \\ VALORES DA PRODUÇÃO NACIONAL DE AZEITE, A PREÇOS CORRENTES}

\begin{tabular}{ccccc}
\hline Ano & 1993 & 1994 & 1995 & 1996 \\
\hline Produção (10 6 escudos) & 11237 & 18263 & 17978 & 24190 \\
\hline
\end{tabular}

Fonte: INE, Estatisticas Agricolas (1993 a 1997).

Depois de salientada a dimensão económica do mercado do azeite, passamos à apresentação de alguns dados relativos à produção. Para o período de 1989 a 1996, apresentam-se no Quadro II informações sobre a produção nacional de azeite.

\section{Quadro II}

PRODUÇÃO NACIONAL DE AZEITE E RENDIMENTO POR HECTARE

\begin{tabular}{lccccc}
\hline & $1989 / 93$ & 1993 & 1994 & 1995 & 1996 \\
\hline Superfície (ha) & 255385 & 258878 & 255153 & 309415 & 311683 \\
Produção (hl) & 390905 & 350779 & 345433 & 477728 & 516000 \\
Rendimento (hl/ha) & 1,53 & 1,35 & 1,35 & 1,54 & 1,66 \\
\hline
\end{tabular}

Fonte: INE, Estatísticas Agrícolas (1993 a 1997).

Quer a superfície cultivada com oliveiras, quer a produção de azeite, têm vindo a aumentar desde 1993, com uma ligeira quebra no ano de 1994. Verifica-se que o rendimento produtivo pode variar significativamente em cada ano agrícola, influenciado pelas condições climatéricas. Nos anos de 1993 e 1994 o rendimento foi baixo, tendo aumentado bastante em 1996. Informações disponiveis, a partir de 1996, indicam que irão ocorrer quebras nas produções dos anos seguintes. $O$ gráfico I pretende ilustrar a variação ocorrida no período estudado.

A quantidade total produzida dá-nos apenas informação bastante genérica sobre o mercado do azeite. Para complementar estes dados "em bruto", torna-se necessário obter o rendimento por quantidade de azeitona, expresso em hectolitros de azeite por tonelada daquela e, além disso, quantificar a qualidade do azeite produzido. Por este motivo apresentam-se também as quantidades produzidas dos vários tipos de azeite (de acordo com o grau de acidez). Estes dados são fornecidos no Quadro III. 


\section{Gráfico I \\ VARIAÇÃO DA PRODUÇÃO NACIONAL DE AZEITE}

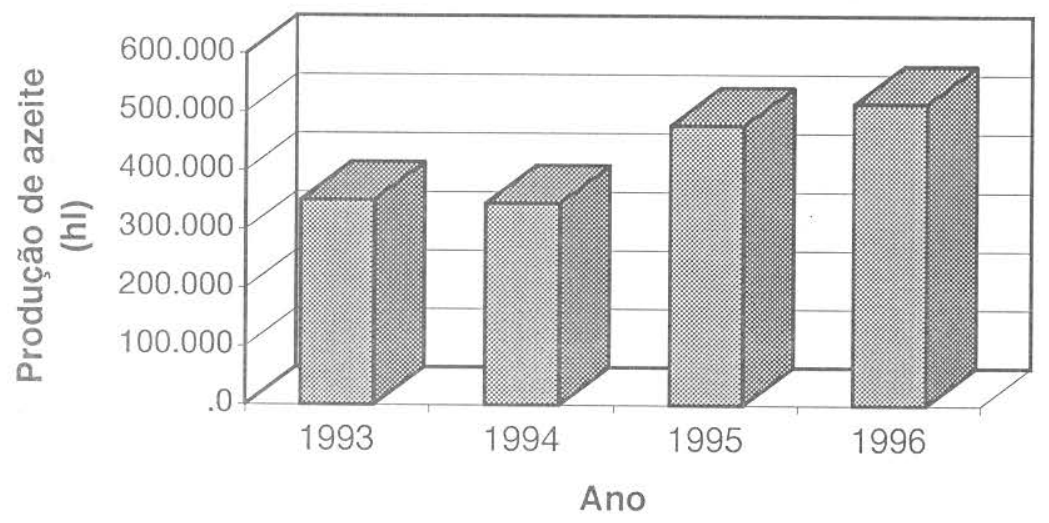

Fonte: INE, Estatísticas Agrícolas (1993 a 1997), elaboração do autor.

\section{Quadro III}

PRODUÇÃO NACIONAL DE AZEITE, RENDIMENTO POR TONELADA DE AZEITONA E DISTRIBUIÇÃO POR GRAUS DE ACIDEZ

\begin{tabular}{lcccc}
\hline & 1992 & 1993 & 1994 & 1995 \\
\hline$N^{\circ}$ lagares & 1013 & 1030 & 1096 & 1125 \\
\hline Azeitona oleificada (t) & 140625 & 237179 & 222210 & 311257 \\
\hline Azeite obtido (hl) & & & & \\
$\quad$ Total & 225000 & 350779 & 345433 & 477728 \\
$\quad$ por tonelada de azeitona & 1,60 & 1,48 & 1,55 & 1,54 \\
\hline Azeite virgem obtido (hI) & & & & \\
Extra $\left(<1^{\circ}\right)$ & 95625 & 127872 & 49054 & 116486 \\
Fino $\left(1.1^{\circ}\right.$ a $\left.2^{\circ}\right)$ & 87750 & 128041 & 108118 & 160870 \\
Corrente $\left(2.1^{\circ} \mathrm{a} 3.3^{\circ}\right)$ & 31275 & 56633 & 97704 & 116999 \\
Lampante $\left(>3.3^{\circ}\right)$ & 10350 & 38233 & 90557 & 83373 \\
\hline
\end{tabular}

Fonte: INE, Estatísticas Agrícolas (1993 a 1997). 
$\mathrm{Da}$ análise deste quadro, pode verificar-se que o número de lagares tem aumentado ligeiramente ao longo dos anos. Considerações bastante mais relevantes são o facto de que:

- o azeite obtido em função da quantidade de azeitona varia de ano para ano: o ano de maior rendimento foi 1992, enquanto que em 1993 se produziu menos azeite por quantidade de azeitona;

- a distribuição do azeite pelos vários tipos de azeite virgem produzidos (extra, fino, corrente e lampante) varia também bastante.

Não é apenas o rendimento de azeite por hectare de olival que condiciona a produção anual, como se concluía do Quadro II, mas também o rendimento de azeite por quantidade de azeitona e a distribuição da produção de azeite virgem pelos vários tipos de azeite (definidos pelo grau de acidez), com maior ou menor qualidade. Todos estes factores são influenciados grandemente pelas condições climatéricas que ocorrem em cada ano agrícola. Deste modo, é difícil prever com precisão o azeite produzido anualmente, pois a variável mais importante não é controlada pelos agricultores. Podem assim acontecer anos de produção bastante elevada e anos de menor produção.

Para se ilustrar melhor a distribuição da produção pelos vários tipos de azeite virgem, de acordo com o grau de acidez, apresenta-se o Gráfico II, em que se identificam as percentagens produzidas anualmente de azeite de qualidade extra, fino, corrente e lampante. 


\section{Gráfico II \\ DISTRIBUIÇÃO DA PRODUÇÃO NACIONAL DE AZEITE POR GRAUS DE ACIDEZ}

1992

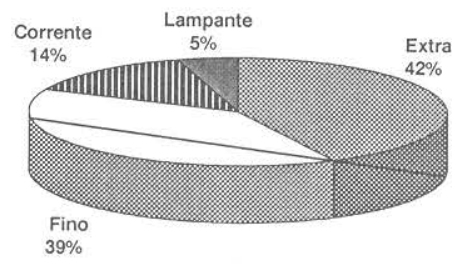

1994

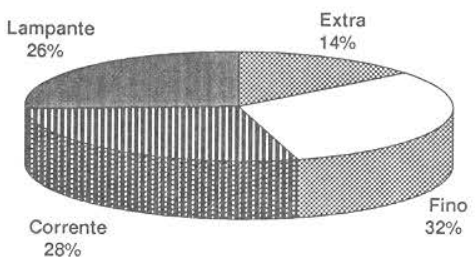

1993

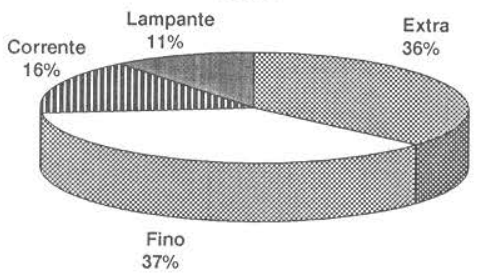

1995

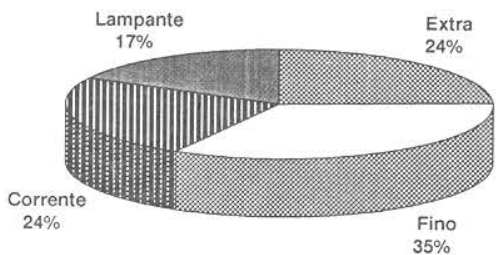

Fonte: INE, Estatísticas Agrícolas (1993 a 1997), elaboração do autor.

A distribuição pelos vários tipos de azeite produzidos varia significativamente de ano para ano. Podemos verificar uma diminuição relativa das produções de azeite de maior qualidade (fino e extra), quando comparadas com as produções de azeite corrente e lampante. Mais uma vez se deve salientar que as variações ocorridas no passado, por influência do clima, não são passíveis de correlação para previsões futuras.

Para complementar este tópico, apresenta-se, no Quadro IV, a título exemplificativo para o ano de 1995, a desagregação da produção nacional de azeite virgem por cinco zonas (Norte, Centro, Lisboa e Vale do Tejo, Alentejo e Algarve), bem como os rendimentos obtidos em cada zona e a distribuição pelos vários tipos de azeite virgem (extra, fino, corrente e lampante). 


\section{Quadro IV \\ PRODUÇÃO DE AZEITE POR REGIÔES E POR GRAUS DE ACIDEZ EM 1995}

\begin{tabular}{lcccccc}
\hline & \multicolumn{5}{c}{ Azeite obtido } & \multicolumn{3}{c}{ Azeite virgem obtido } \\
\hline & $\begin{array}{c}\text { por ton. de } \\
\text { azeitona }\end{array}$ & Total & $\begin{array}{c}\text { Extra } \\
\left(<1^{\circ}\right)\end{array}$ & $\begin{array}{c}\text { Fino } \\
\left(1,1^{\circ} \text { a } 2^{\circ}\right)\end{array}$ & $\begin{array}{c}\text { Corrente } \\
\left(2,1^{\circ} \text { a } 3,3^{\circ}\right)\end{array}$ & $\begin{array}{c}\text { Lampante } \\
\left(>3,3^{\circ}\right)\end{array}$ \\
& $(\mathrm{hl} / \mathrm{t})$ & $(\mathrm{hl})$ & \multicolumn{1}{c}{$(\mathrm{hl})$} & $(\mathrm{hl})$ & $(\mathrm{hl})$ & $(\mathrm{hl})$ \\
\hline Norte & 1,78 & 147671 & 34658 & 59426 & 37242 & 16346 \\
Centro & 1,43 & 135528 & 27000 & 41260 & 41964 & 25303 \\
Lisboa e Vale do Tejo & 1,35 & 58800 & 11025 & 22373 & 14959 & 10444 \\
Alentejo & 1,49 & 119629 & 42362 & 35176 & 20472 & 21619 \\
Algarve & 1,67 & 16101 & 1441 & 2636 & 2363 & 9661 \\
\hline Total & 1,53 & 477729 & 116486 & 160871 & 117000 & 83373 \\
\hline
\end{tabular}

Fonte: INE, Estatisticas Agricolas (1996).

No Quadro IV pode observar-se a diversidade de rendimento, medido em hectolitros por tonelada de azeite, para cada uma das zonas estudadas, mais uma vez função, certamente, da variedade específica de oliveira e de condicionalismos do clima em cada região. Além disso, recorrendo a dados para outros anos, o rendimento em cada região também se apresenta pouco uniforme. A distribuição da produção pelas várias regiões do país permite identificar o Norte como a principal região produtora, seguida pela região Centro e Alentejo e, com produções inferiores, Lisboa e Vale do Tejo e, finalmente, o Algarve com menor produção.

No Gráfico III ilustra-se a distribuição da produção nacional de azeite pelas cinco regiões, em 1995, para uma melhor apreensão pelo leitor. 


\section{Gráfico III \\ DISTRIBUIÇÃO DA PRODUÇÃO NACIONAL DE AZEITE POR REGIÕES EM 1995}

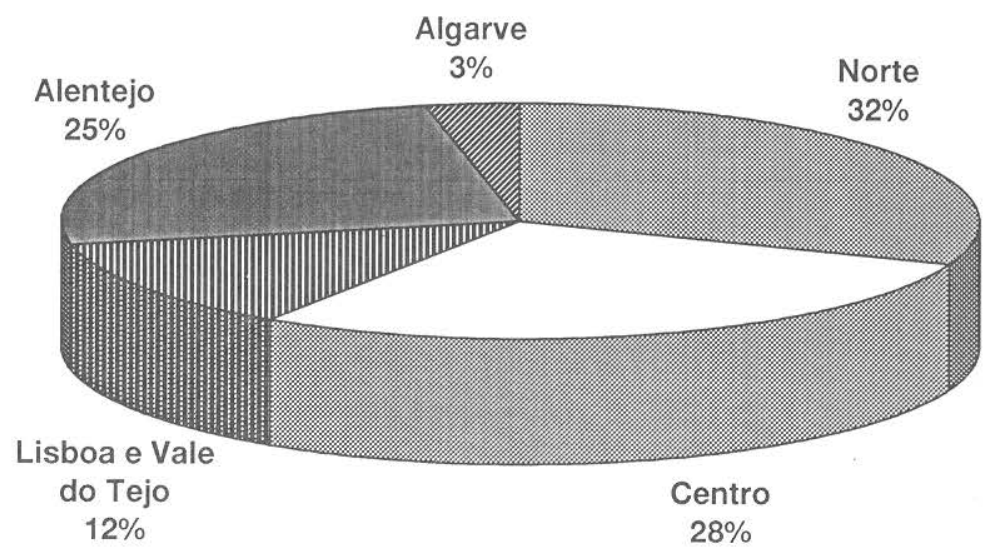

Fonte: INE, Estatísticas Agrícolas (1996), elaboração do autor.

Do Quadro IV retira-se também informação sobre a distribuição da produção de azeite virgem, em cada região, pelas respectivas qualidades de azeite virgem (extra, fino, corrente e lampante). Para melhor ilustrar esta distribuição, apresenta-se o gráfico IV.

Analisando o gráfico, verifica-se que a produção relativa de azeite fino diminui à medida que nos deslocamos de Norte para Sul, ao longo de todo o país, com a excepção da região de Lisboa e Vale do Tejo. O mesmo sucede com o azeite de qualidade extra, com a excepção do Alentejo. Quanto à produção relativa de azeites de menor qualidade (corrente e lampante), ela é menor no Norte e no Alentejo, tendo níveis semelhantes no Centro, Lisboa e Vale do Tejo, sendo bastante significativa no Algarve.

Conclui-se destas observações que, em termos relativos, nas regiões Norte e Alentejo são produzidos azeites de qualidade superior. A região Centro, Lisboa e Vale do Tejo, ocupam posições intermédias, quanto ao nível de qualidade do azeite nelas produzido e, no Algarve, as menores quantidades produzidas apresentam uma qualidade mais baixa. Para a análise deste gráfico entenda-se, por qualidade, o grau de acidez do azeite virgem. 
Para tecer as considerações de nível económico necessárias a este trabalho, torna-se imprescindível conhecer o valor económico, obtido a partir dos preços médios anuais de cada tipo de azeite (em função do grau de acidez). No Quadro V são apresentados esses preços médios anuais do azeite produzido em Portugal, de acordo com a sua qualidade.

\section{Gráfico IV \\ DISTRIBUIÇÃO DA PRODUÇÃO NACIONAL DE AZEITE POR REGIÕES E POR GRAUS DE ACIDEZ EM 1995}
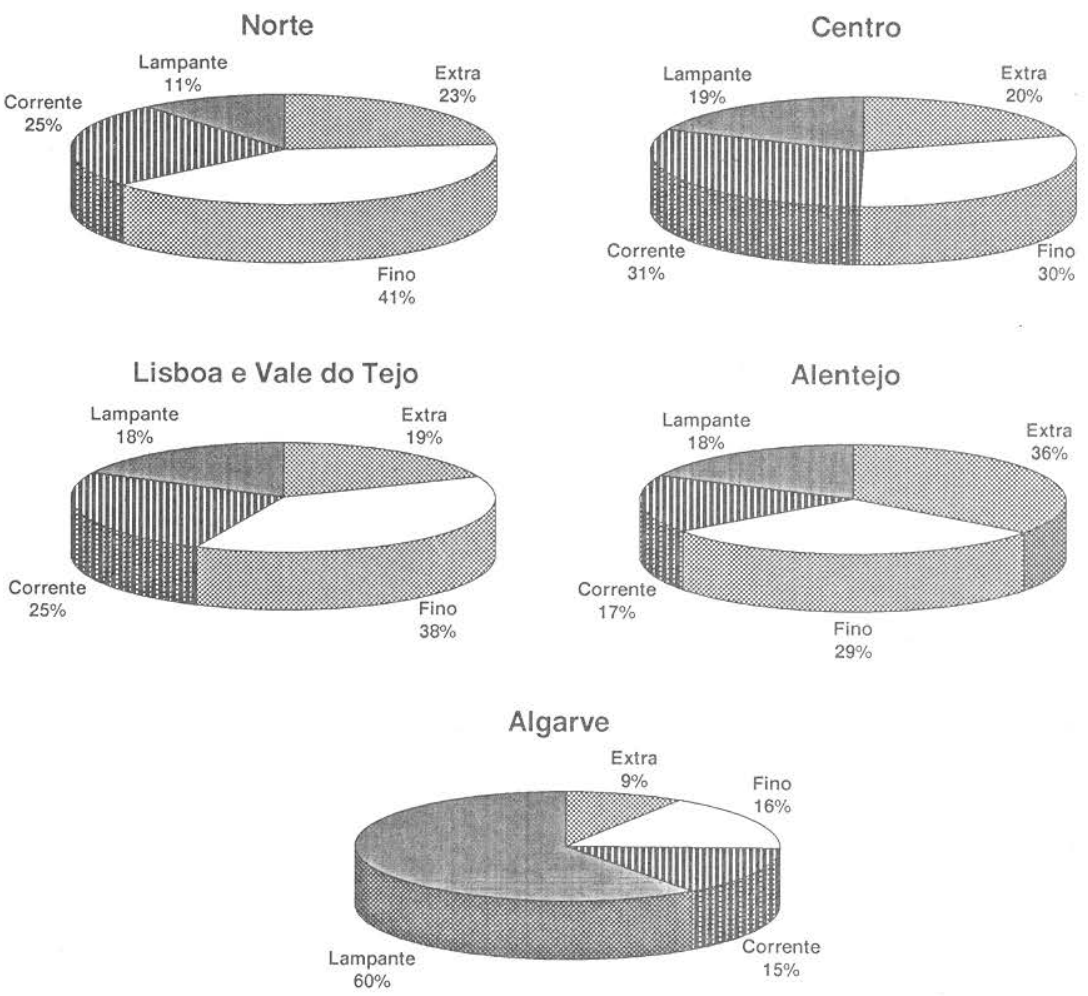

Fonte: INE, Estatísticas Agrícolas (1996), elaboração do autor. 


Quadro V
PREÇOS ANUAIS MÉDIOS (EM ESCUDOS POR LITRO) DO AZE E
PRODUZIDO EM PORTUGAL POR GRAU DE ACIDEZ
\begin{tabular}{ccccc}
\multicolumn{4}{c}{} \\
\hline Azeite Virgem (Esc./1) & 1993 & 1994 & 1995 & 1996 \\
\hline Extra & $468 \$ 71$ & $591 \$ 73$ & $676 \$ 89$ & $931 \$ 96$ \\
Fino & $426 \$ 08$ & $526 \$ 18$ & $510 \$ 10$ & $704 \$ 14$ \\
Corrente & $405 \$ 00$ & $501 \$ 06$ & $467 \$ 09$ & $692 \$ 54$ \\
Lampante & $370 \$ 00$ & $459 \$ 34$ & $443 \$ 33$ & $664 \$ 16$ \\
\hline
\end{tabular}

Fonte: INE, Estatísticas Agrícolas (1993 a 1997).

Ao longo dos anos estudados ocorreu uma subida relevante do preço de todos os tipos de azeite virgem, que é notada especialmente de 1995 para 1996. O aumento de preço é tanto mais significativo, quanto maior é a qualidade do azeite, em termos de grau de acidez. Esta variação bastante positiva de preços é, certamente, consequência da cada vez maior importância dada a uma dieta saudável, que provoca aumento na procura e consumo de azeite, originando esta escalada de preços.

Por fim, é importante ter uma ideia das importações e exportações de azeite realizadas por Portugal. No Quadro VI apresentam-se dados relativos de 1994 a 1996.

\section{Quadro VI}

IMPORTAÇÕES E EXPORTAÇÕES DE AZEITE EM PORTUGAL, DE 1994 A 1996

\begin{tabular}{lcccrcc}
\hline & \multicolumn{3}{c}{ Importações } & \multicolumn{3}{c}{ Exportações } \\
& 1994 & 1995 & 1996 & 1994 & \multicolumn{1}{c}{1995} & 1996 \\
\hline Toneladas & 35208 & 40435 & 29073 & 11558 & 15059 & 14345 \\
$10^{6}$ Escudos & 15559 & 21905 & 21789 & 4936 & 8420 & 11974 \\
Esc./1 & $485 \$ 64$ & $595 \$ 32$ & $823 \$ 58$ & $469 \$ 31$ & $614 \$ 40$ & $917 \$ 23$ \\
\hline
\end{tabular}

Fonte: INE, Estatísticas Agrícolas (1994 a 1997), elaboração do autor.

Portugal apresenta-se como um país deficitário na produção de azeite, importando anualmente quantidades superiores às exportadas. Nos dois últimos anos analisados, o valor de cada litro de azeite exportado é superior 
ao valor do litro de azeite importado, pelo que se pode sugerir que o azeite exportado terá, em média, uma qualidade superior à do azeite importado.

\section{UM NOVO MÉTODO DE REFINAÇÃO DE AZEITE}

\subsection{Apresentação da extracção supercrítica}

A designação fluidos supercríticos refere-se a substâncias que se encontram a valores de pressão bastante superiores à pressão atmosférica, que alteram as características "normais" das referidas substâncias. Para definir um fluido supercrítico, podemos apresentar o exemplo simplista de água a ferver numa panela de pressão: existe água na forma líquida e na forma de vapor. Se aumentarmos a pressão e a temperatura, atinge-se um ponto em que as formas líquidas e vapor se fundem numa única forma fluida, denominada fase supercrítica. Pode dizer-se que existe, além dos três estados normais da matéria (sólido, líquido e gasoso), um outro estado, desconhecido do comum dos mortais, denominado por estado supercrítico.

Os fluidos supercríticos possuem um poder solvente ajustável, ou seja, mediante pequenas variações de pressão e temperatura, atingem a capacidade de dissolver sólidos e líquidos, sendo também fácil precipitar os compostos previamente dissolvidos. Estas características tornam estes fluidos meios de extracção privilegiados para, por exemplo, separar um componente de uma mistura (Pereira, 1995).

A Extracção Supercrítica é uma técnica de separação (entenda-se extracção de um ou mais componentes de uma mistura) que utiliza, como é óbvio, os fluidos supercríticos. Apresenta a vantagem, quando comparada, por exemplo, com a destilação, de poder ser utilizada a temperaturas muito próximas da ambiente. A extraç̧ão com fluidos supercríticos pode substituir processos de separação clássicos, especialmente quando em operações com substâncias que venham a ser incluídas no ciclo biológico humano ou que se degradem por acção da temperatura.

O solvente mais usual em processos de extracção é o dióxido de carbono, por ser não tóxico, não poluente, não inflamável e barato. Este solvente não deixa resíduos, quer nos produtos separados, quer na mistura de onde se faz a extracção, pelo que o método pode considerar-se ecologicamente vantajoso e ideal para a saúde pública. Indústrias como a alimentar, farmacêutica e dos óleos, actualmente sensíveis a estes problemas, apresentam-se como um potencial campo de aplicação da Extraç̧ão Supercrítica.

$\mathrm{Na}$ indústria alimentar, a Extracção Supercrítica é utilizada na descafeinação natural do café e chá, extracção de lúpulos para o fabrico de 
cerveja, extracção da nicotina do tabaco, purificação e fabrico de fármacos, extracção de sabores e aromas, entre outros (Hubert e Vitzhum, 1978). Estes exemplos dizem respeito à extraç̧ão de produtos sólidos. As aplicações à extracção de líquidos, mais difíceis de desenvolver e projectar, encontram-se apenas, nos últimos tempos, na Europa, E.U.A. e sobretudo no Japão (Böhm et al., 1989).

Os resultados de muitos estudos de viabilidade económica de processos de extracção aparecem descritos na literatura (Schneider et al., 1980; Penninger et al., 1985; Johnston e Penninger, 1989). A conclusão geral é que os processos, usando fluidos supercríticos, apesar de todas as vantagens inerentes, são mais caros quando comparados com as técnicas convencionais, tais como a destilação e a extracção, em consequência das altas pressões requeridas (exigindo, por exemplo, altos custos de bombagem de fluidos e equipamento e necessitando de mais atenção relativamente a problemas de segurança, materiais de construção, etc.). Contudo, os processos de extracção supercrítica podem ser economicamente atractivos para produtos de alto valor acrescentado ou quando as técnicas convencionais forem menos apelativas para o consumidor do produto final.

\subsection{Aplicação da extracção supercrítica à refinação de azeite}

A aplicação da extracção supercrítica a processos de purificação de produtos naturais para consumo humano é uma área privilegiada. $O$ azeite é um produto sobejamente conhecido e valioso, sobretudo quando vendido como produto virgem, obtido por prensagem a frio e sem tratamento químico posterior. A refinação tradicional dos azeites ácidos altera significativamente o seu perfil, daí resultando um produto menos valioso. Em termos das tendências actuais dos mercados mais sofisticados, qualquer tratamento químico representa uma desvantagem significativa, pela resultante imagem negativa na opinião pública. Por outro lado, o azeite tem tido dificuldades em se impor nos mercados mais ricos do Norte, apesar da actual tendência de sobrevalorização da dieta mediterrânica, por razões médicas. Um processo de refinação que comprovadamente mantivesse as características "naturais" do azeite e, em simultâneo, o desacidificasse e desaromatizasse, adaptando-o aos gostos de mercados não habituados ao forte aroma do azeite virgem, representaria uma oportunidade de valorização significativa deste produto.

A utilização de extracção com fluidos supercríticos na indústria de óleos alimentares tem sido sugerida por diversos autores: a desacidificação e desodorização de gorduras e óleos vegetais foram propostas em patentes por 
Zozel, Coenen e Kriegel. Brunetti et al. sugerem a utilização de extracção com $\mathrm{CO}_{2}$ supercrítico na desacidificação de azeite.

Nunes da Ponte et al. (1992) e Carmelo (1995) definiram, à escala laboratorial, as condições a utilizar na extracção de ácidos gordos (nomeadamente o ácido oleico) do azeite, com vista à sua desacidificação, sem alterar as suas qualidades nutricionais. Pode-se, portanto, a partir de um azeite com elevado grau de acidez, obter um produto de composição comparável à de um azeite virgem. Esta afirmação é consubstanciada pelo seguinte facto: um modo de verificar se um azeite se encontra degradado, pelo processo de refinação, consiste numa análise que tem por objectivo identificar a presença de um composto (estigmasta-3,5-dieno) no azeite desacidificado, uma vez que a presença desse composto resulta da degradação do sitosterol pelos processos usuais de refinação do azeite.

Aplicando um procedimento analítico, descrito na norma padrão publicada no Jornal Oficial da Comunidade Europeia (1991), usada para diferenciar um azeite virgem de um refinado, detectou-se a presença do composto apresentado previamente num azeite refinado adquirido no mercado, mas o mesmo composto não apareceu no azeite refinado por extracção supercrítica. Este exemplo é apresentado para ilustrar como se torna fácil provar a diferença entre dois azeites, um refinado por extracção supercrítica e outro por métodos tradicionais.

Os estudos de Nunes da Ponte et al. (1992) e Carmelo (1995) são fundamentais para definir vários parâmetros operacionais, tais como a pressão e temperatura de extracção, pressão de separação, recirculação de solvente que permitem dimensionar um processo de Extracção Supercrítica e, também, para a obtenção de modelos matemáticos que possam ser utilizados no dimensionamento e scale-up de uma unidade industrial de extracção supercrítica, de modo a possibilitar a avaliação técnico-económica do processo testado laboratorialmente.

As experiências realizadas evidenciam uma grande selectividade para a fracção de ácidos gordos livres, presentes na mistura. Assim, em relação ao problema que nos propusemos abordar, a apreciação global é francamente positiva para a desacidificação do azeite.

As selectividades para a fracção de ácidos gordos livres são altas e o processo de desacidificação é viável. São utilizados modelos para descrever o processo de extracção supercrítica, que servirão de base a cálculos de scale-up para o dimensionamento do equipamento necessário ao processo de extracção industrial. O modelo que apresentou melhores resultados foi o de Haan e de Graauwt (1991). 


\section{ESTUDO DE SCALE-UP DE UMA UNIDADE INDUSTRIAL PARA A REFINAÇÃO DE AZEITE POR EXTRACÇÃO SUPERCRÍTICA}

Será feito, de seguida, um breve estudo de scale-up - que consiste no dimensionamento de uma unidade de produção industrial, a partir de estudos realizados a nível laboratorial - para a extracção de ácidos gordos do azeite, utilizando dióxido de carbono supercrítico, a uma pressão de 180 atmosferas e à temperatura de $40^{\circ} \mathrm{C}$, condições definidas pelos estudos laboratoriais atrás referidos: os resultados obtidos demonstram a viabilidade do processo de desacidificação por intermédio do dióxido de carbono em condições supercríticas, sendo possível dimensionar uma unidade industrial de extracção supercrítica para a desacidificação de azeite.

A refinação do azeite, no que diz respeito à sua desacidificação, é um negócio de alto valor acrescentado; os preços aumentam significativamente, quando se diminui o grau de acidez do azeite alimentar (a diferença de preço médio, em 1996, entre o azeite lampante e o azeite extra aproxima-se dos $300 \$ 00$ por litro - Quadro V). A instalação industrial será dimensionada com o propósito de refinar este azeite com alto teor de acidez: azeite lampante, transformando-o em azeite de alta qualidade, com níveis inferiores a $1^{\circ}$ de acidez: azeite extra.

O objectivo consistirá em ter capacidade para refinar grande parte do azeite lampante produzido em território nacional e ainda algum produzido nas províncias vizinhas de Espanha, uma vez que Portugal, pela sua proximidade em relação aquele país, o maior produtor mundial de azeite, se torna assim numa boa localização para a instalação de uma fábrica de refinação e desacidificação de azeite produzido dos dois lados da fronteira.

Tomando como exemplo os anos de 1994 e 1995, verificou-se que as produções de azeite lampante em Portugal se situaram em valores próximos de 90000 hectolitros (ver Quadro III). De modo a facilitar o projecto, as quantidades de azeite serão processadas em unidades mássicas. Sabendo que a um litro de azeite corresponde $1,1 \mathrm{~kg}$, a 90000 hectolitros corresponderão aproximadamente 10000 toneladas de azeite. Para efectuar o dimensionamento duma unidade industrial é necessário fixar a sua capacidade de produção. Tivemos por base de cálculo a hipótese de que, na unidade industrial, conseguiríamos proceder à desacidificação de parte da produção nacional mais uma parte da produção de Espanha.

Deste modo, optámos por fixar a capacidade anual de processamento em 10000 toneladas de azeite lampante (com alto teor de acidez). Tomámos como objectivo produzir azeite desacidificado, refinado por um processo que pode ser apresentado como "natural" em mercados mais sofisticados. 
O diagrama esquemático da unidade de extracção é apresentada na Figura I, representando-se as correntes pelos algarismos de um a dez. A alimentação consiste em azeite lampante a desacidificar, o refinado é o azeite desacidificado e o extracto é composto essencialmente de ácidos gordos. Tem-se o cuidado de se proceder à regeneração e recirculação do solvente (dióxido de carbono), de modo a que este não constitua um elemento poluente.

Figura I

DIAGRAMA ESQUEMÁTICO DA UNIDADE INDUSTRIAL DE EXTRACÇÃO SUPERCRÍTICA: REFINAÇÃO (DESACIDIFICAÇÃO) DE AZEITE

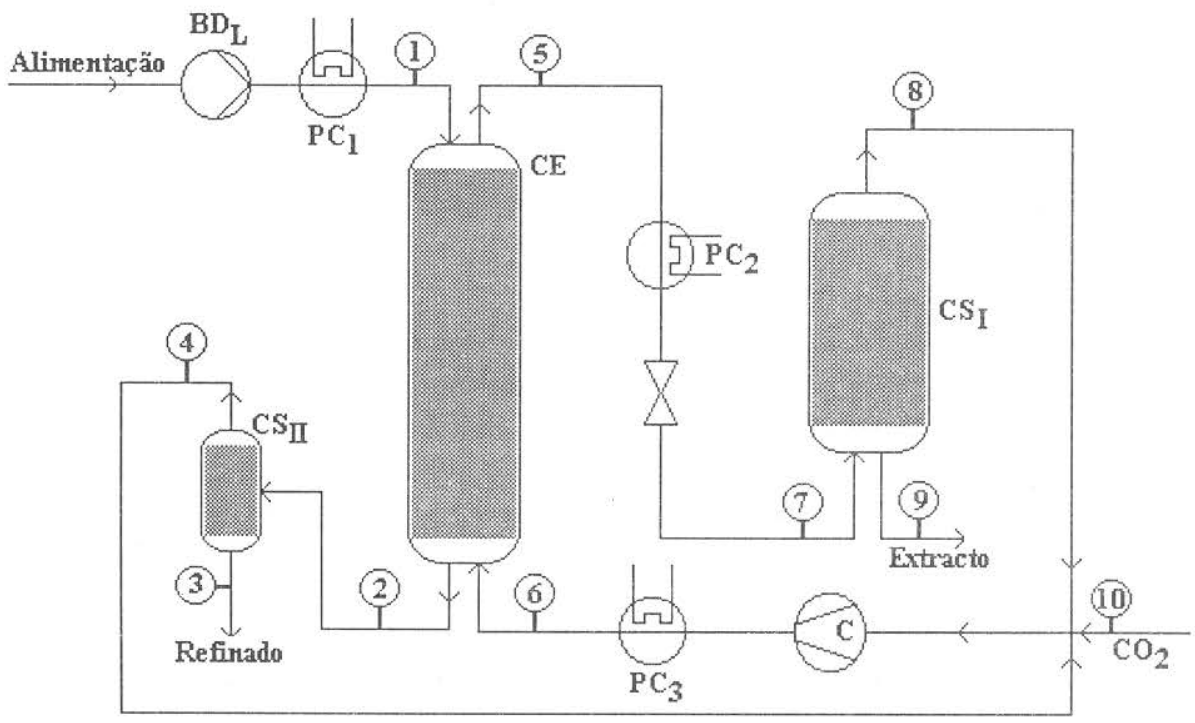

Legenda: $\mathrm{CO}_{2}$ - Dióxido de carbono; $\mathrm{BD}_{\mathrm{L}}$ - Bomba doseadora de azeite; $\mathrm{C}$ - Compressor de $\mathrm{CO}_{2}$; PC - Permutadores de calor; CE - Coluna de extraç̧ão; CS - Colunas de separação.

A capacidade anual de 10000 toneladas de azeite com teor de ácidos gordos superior a 3,3\% (azeite lampante) corresponde a uma alimentação de $1389 \mathrm{~kg} / \mathrm{hr}$ (em contínuo, 300 dias/ano). As condições de extracção serão uma pressão de 180 atmosferas e uma temperatura de $40^{\circ} \mathrm{C}$, que não provoca degradação do azeite. Na coluna de separação utiliza-se uma pressão de 80 atmosferas e uma temperatura de $50^{\circ} \mathrm{C}$. Utilizando os dados obtidos nos 
ensaios laboratoriais, podem-se definir as composições de entrada e de saída da unidade industrial.

\subsection{Dimensionamento do equipamento}

O diâmetro da coluna de extracção é determinado, recorrendo ao método de dimensionamento aconselhado por um fabricante de colunas (Sulzer Brothers Ltd., 1991), sendo de aproximadamente 1,14 m. A altura é obtida recorrendo ao modelo desenvolvido por Bravo et al. (1985), sendo a altura total de enchimento da coluna industrial estimada em aproximadamente três metros. Adicionando uma percentagem arbitrária, de 30\% de altura, à coluna (como margem de segurança), temos uma altura total de coluna de quatro metros. A espessura da coluna também pode ser calculada em função da pressão de trabalho (Coulson e Richardson, 1983), obtendo-se uma espessura de $9,5 \mathrm{~cm}$. Tendo em conta o valor do diâmetro, espessura e altura da coluna, a massa específica do aço $\left(7,1 \mathrm{~kg} / \mathrm{dm}^{3}\right)$ e o preço unitário do aço (3500\$00/kg), estimou-se o custo da coluna. Acrescentou-se um factor, normalmente utilizado, de $200 \%$, para os custos de mão-de-obra e demais equipamento acessório, tendo-se atingido o valor de 87591 contos. O custo do enchimento a utilizar, Sulzer BX, foi estimado em 244280 contos (822 contos $/ \mathrm{dm}^{3}$ ). O custo básico total da coluna e enchimento é de 331872 contos.

Fazendo os cálculos do mesmo modo que anteriormente, estima-se um diâmetro da coluna de separação $\left(\mathrm{CS}_{\mathrm{II}}\right)$ de $1,25 \mathrm{~m}$ e uma altura de enchimento correspondente de $2,84 \mathrm{~m}$. A espessura é estimada em $4,5 \mathrm{~cm}$. O custo total básico é estimado em 9828 contos. No caso da coluna de separação $\left(\mathrm{CS}_{\mathrm{I}}\right)$, o diâmetro da coluna é estimado em $0,21 \mathrm{~m}$ e a altura de enchimento de $3,2 \mathrm{~m}$, sendo a espessura da parede da coluna de $1,0 \mathrm{~cm}$, atingindo-se um custo total de 311835 contos, superior ao anterior devido ao enchimento.

A estimativa do custo dos permutadores de calor é feita recorrendo ao modelo de projecto apresentado por Cygnarowicz e Seider (1990), obtendo-se os valores de 443 contos, 1538 contos e 1416 contos, para os permutadores de calor $\mathrm{PC}_{1}, \mathrm{PC}_{2}$ e $\mathrm{PC}_{3}$, respectivamente.

$\mathrm{O}$ dimensionamento e estimativa de preços do compressor de gases e da bomba doseadora de líquidos foi feito recorrendo a dados fornecidos pelo fabricante e através do método proposto por Cygnarowicz e Seider (1990), obtendo-se os valores de 30570 contos e 22179 contos, respectivamente. 


\subsection{Estudo de viabilidade económica}

No sentido de demonstrar a viabilidade deste projecto de implantação duma instalação industrial, para a desacidificação de azeite por extracção supercrítica, será realizada uma avaliação económica, baseada em publicações na área de análise de projectos (Ross et al., 1996; Bierman e Smidt, 1993; Barros, 1994). O estudo de viabilidade económica ${ }^{3}$ tem por base uma simulação de todas as despesas e receitas envolvidas numa instalação industrial (Peters e Timmerhaus, 1980).

O objectivo principal deste estudo é o de permitir uma primeira abordagem à questão da rentabilidade económica do projecto, pois baseou-se nas experiências preliminares efectuadas à escala laboratorial, necessitando, como tal, de validação posterior.

Valores de input importantes para este estudo dizem respeito ao ano de arranque, tendo-se escolhido o ano 2000 para início de laboração, operando a fábrica 300 dias úteis por ano, com 24 horas de trabalho diário, pois trata-se de um processo em contínuo. Serão tratadas anualmente, nesta unidade industrial, 10000 ton. de azeite lampante, que originarão, após extracção dos ácidos gordos, 8950 ton. de azeite desacidificado, de qualidade extra. Admite-se que, no primeiro e segundo ano, a laboração atinja os $60 \%$ e os $80 \%$, respectivamente, atingindo-se a capacidade máxima em 2002.

Para preço de venda do azeite desacidificado, de qualidade extra, adoptou-se um valor de $1100 \$ 00$ por quilograma de azeite extra (corresponde a $1000 \$ 00$ por litro), tendo por base os valores do Quadro V. O preço de compra de azeite lampante é estimado a partir dos dados do mesmo Quadro, sendo previsto o valor de $700 \$ 00$ por quilograma de azeite lampante (corresponde a $682 \$ 50$ por litro). O dióxido de carbono é adquirido a um preço de $150 \$ 00$ por quilograma, sendo necessária uma utilização anual de 1200 ton.

Todos os fornecimentos e serviços de terceiros são estimados ou calculados empiricamente em função do estudo de scale-up . No Quadro VII apresenta-se um resumo dos custos de equipamento, previamente calculados de modo empírico. 


\section{Quadro VII \\ CUSTOS DE EQUIPAMENTO}

\begin{tabular}{lc}
\hline Equipamento & Preço (contos) \\
\hline Coluna de Extracção & 331872 \\
Coluna de Separação I & 311835 \\
Coluna de Separação II & 9828 \\
\hline Permutador de Calor I & 443 \\
Permutador de Calor II & 1538 \\
Permutador de Calor III & 1416 \\
\hline Compressor & 30570 \\
Bomba Doseadora & 22179 \\
Bomba Compensadora & 8987 \\
\hline Adicional de 15\% para válvulas, tubos, ligaçães, & 107890 \\
manómetros, medidores de caudal e de temperatura & 827158 \\
\hline TOTAL & \\
\hline
\end{tabular}

O financiamento do investimento é realizado através de um empréstimo bancário, com um juro semestral de $3,5 \%{ }^{4}$, que corresponde a uma taxa de juro efectiva anual de $7,12 \%$.

O estudo de viabilidade economica é apresentado de forma desenvolvida em Anexo. De seguida, serão referidas as conclusões mais importantes inferidas do estudo.

Utilizou-se a taxa interna de rentabilidade (TIR) como método de avaliação deste projecto de investimento. No Quadro A.18, podemos verificar que se obteve uma $\mathrm{TIR}=24,3 \%$, calculada a partir do valor actualizado líquido para o período de tempo estudado. $O$ valor da TIR indica que este projecto de investimento apresenta uma rentabilidade superior a bastantes taxas que possam ser tomadas como referência (por exemplo, das obrigações do tesouro e do valor da taxa de juro para depósitos a prazo), podendo, numa primeira análise, ser implementado com vantagens económicas para o investidor. No entanto, este valor da TIR tem de ser encarado com algumas reticências, uma vez que a análise de sensibilidade (Quadro A.20) revela grandes quebras naquela: a diminuição dos proveitos em $10 \%$, mantendo os custos constantes, origina uma TIR negativa e o aumento dos custos em 10\%; permanecendo os proveitos constantes, provoca diminuição da TIR para 5,1\%. Variações nos preços de mercado podem influenciar grandemente a viabilidade deste projecto. 
Os indicadores financeiros (Quadro A.22) fornecem-nos alguma informação complementar sobre a saúde financeira e económica do projecto de investimento, nomeadamente sobre o seu grau de equilíbrio, bem como a correspondência entre as aplicações e os recursos, estabelecendo relações entre as grandezas do balanço previsional.

A liquidez geral, razão entre o activo circulante e o passivo de curto prazo, apresenta sempre valores superiores à unidade, indicando que o projecto tem capacidade para solver os compromissos no curto prazo. $\mathrm{O}$ valor de 2,4 no ano de 2004 é já um bom indicador.

A autonomia financeira, razão entre os capitais próprios e o activo global, representa a capacidade de recorrer a capital alheio. A solvabilidade, razão entre os capitais próprios e o passivo, representa a capacidade de solver os problemas a médio e longo prazo. Nenhum dos indicadores compromete a viabilidade do projecto: por exemplo, no ano de 2004 a empresa denota já uma maioria de capitais próprios e tem capacidade para garantir o passivo.

$O$ fundo de maneio, diferença entre os capitais permanentes e o imobilizado líquido, assegura $\circ$ financiamento de parte dos capitais circulantes, dado que existem elementos cuja rotação habitual é demasiado lenta e que não se coadunam com a exigibilidade das dívidas a curto prazo, pelo que se torna necessário dispor de uma margem de segurança. $O$ fundo de maneio tem sempre um valor positivo. Já a tesouraria, diferença entre o fundo de maneio e as necessidades de fundo de maneio, apresenta valores positivos apenas no primeiro e último ano do estudo realizado, o que vem comprometer o equilíbrio financeiro nos restantes anos.

Através deste breve estudo de viabilidade económica, pode concluir-se que a aplicação deste projecto a um nível industrial é, numa primeira análise, economicamente viável. Esta análise prévia deve ser suportada por um estudo mais aprofundado, de modo a garantir a aplicação prática do mesmo.

\section{NOTAS}

1 Segundo classificação proposta pelo Instituto Nacional de Estatística, Portugal, na sua publicação periódica anual Estatísticas Agrícolas.

2 o estudo de scale-up consiste, basicamente, no dimensionamento de uma instalação de dimensão industrial a partir de dados recolhidos a um nível laboratorial ou à escala piloto.

3 Para uma facilidade de cálculos, todo este estudo foi efectuado considerando uma análise a preços constantes em lugar de preços reais, pelo que poderão existir ligeiras 
flutuações nos resultados. Refira-se também que a unidade monetária usada é milhares de escudos (contos) e as produções de azeite expressam-se em toneladas.

4 Tomou-se como referência a taxa de juro anual Lisbor a seis meses, à qual foi acrescido um spread de aproximadamente $2,5 \%$. 


\section{ANEXO \\ ESTUDO DE VIABILIDADE ECONÓMICA}

\section{A.1 - Produção de azeite desacidificado, de qualidade extra}

\begin{tabular}{lrrrrrr}
\hline & Ano & 2000 & 2001 & 2002 & 2003 & 2004 \\
\hline Quantidades produzidas (ton.) & 5370 & 7160 & 8950 & 8950 & 8950 \\
Valor (contos) a $1100 \$ / \mathrm{kg}$ & 5907000 & 7876000 & 9845000 & 9845000 & 9845000 \\
\hline
\end{tabular}

\section{A.2 - "Stock" de produto acabado (PA) 1}

\begin{tabular}{lrrrrrr}
\hline & Ano & 2000 & 2001 & 2002 & 2003 & 2004 \\
\hline Quantidades (ton.) & 537 & 716 & 895 & 895 & 895 \\
Variação em quantidades (ton.) & 537 & 179 & 179 & 0 & 0 \\
\hline Valorização de "stocks" de PA(contos & 590700 & 787600 & 984500 & 984500 & 984500 \\
"Stock" inicial de PA (contos) & 0 & 590700 & 787600 & 984500 & 984500 \\
"Stock" final de PA (contos) & 590700 & 787600 & 984500 & 984500 & 984500 \\
\hline Variação de "stocks" de PA (contos) & 590700 & 196900 & 196900 & 0 & 0 \\
\hline
\end{tabular}

\section{A.3 - Vendas de produto ${ }^{2}$}

\begin{tabular}{lrrrrrrr}
\hline & Ano & 2000 & 2001 & 2002 & 2003 & 2004 \\
\hline Quantidades vendidas (ton.) & 4833 & 6981 & 8771 & 8950 & 8950 \\
\hline Orçamento de vendas (contos) & 5316300 & 7679100 & 9648100 & 9845000 & 9845000 \\
Saldo inicial clientes (contos) & 0 & 873912 & 1262318 & 1585989 & 1618356 \\
Saldo final clientes (contos) & 873912 & 1262318 & 1585989 & 1618356 & 1618356 \\
\hline Recebimento de vendas (contos) & 4442388 & 7290695 & 9324429 & 9812633 & 9845000 \\
\hline
\end{tabular}

A.4-Matérias primas (MP's): orçamento de pagamentos a fornecedores 3

\begin{tabular}{lrrrrrr}
\hline & Ano & 2000 & 2001 & 2002 & 2003 & 2004 \\
\hline Azeite lampante (ton.) & 6000 & 8000 & 10000 & 10000 & 10000 \\
Dióxido de carbono (ton.) & 720 & 960 & 1200 & 1200 & 1200 \\
\hline Azeite lampante a $700 \$ / \mathrm{kg}$ (contos) & 4200000 & 5600000 & 7000000 & 7000000 & 7000000 \\
Dióxido carbono a 150\$/kg (contos) & 108000 & 144000 & 180000 & 180000 & 180000 \\
\hline \multicolumn{1}{c}{ TOTAL } & 4308000 & 5744000 & 7180000 & 7180000 & 7180000 \\
\hline "Stock" inicial de MP's (contos) & 0 & 1292400 & 1723200 & 2154000 & 2154000 \\
"Stock" final de MP's (contos) & 1292400 & 1723200 & 2154000 & 2154000 & 2154000 \\
\hline Compras de MP's (contos) & 5600400 & 6174800 & 7610800 & 7180000 & 7180000 \\
\hline Saldo inicial fornecedores (contos) & 0 & 920614 & 1015036 & 1251090 & 1180274 \\
Saldo final fornecedores (contos) & 920614 & 1015036 & 1251090 & 1180274 & 1180274 \\
\hline Orçamento de pagamentos (contos) & 4679786 & 6080378 & 7374745 & 7250816 & 7180000 \\
\hline
\end{tabular}




\section{A.5 - Fornecimentos e serviços de terceiros ${ }^{4}$ (contos)}

\begin{tabular}{|c|c|c|c|c|c|}
\hline Ano & 2000 & 2001 & 2002 & 2003 & 2004 \\
\hline Água & 24000 & 32000 & 40000 & 40000 & 40000 \\
\hline Energia eléctrica & 48000 & 64000 & 80000 & 80000 & 80000 \\
\hline Combustíveis & 24000 & 32000 & 40000 & 40000 & 40000 \\
\hline Conservação e reparação & 14400 & 19200 & 24000 & 24000 & 24000 \\
\hline Ferramentas utensílios desgaste rápido & 6000 & 8000 & 10000 & 10000 & 10000 \\
\hline Seguros & 4500 & 6000 & 7500 & 7500 & 7500 \\
\hline Transportes & 12000 & 16000 & 20000 & 20000 & 20000 \\
\hline Artigos de expediente & 3000 & 4000 & 5000 & 5000 & 5000 \\
\hline Servicos terceiros, publicidade, etc & 24000 & 32000 & 40000 & 40000 & 40000 \\
\hline TOTAL & 159900 & 213200 & 266500 & 266500 & 266500 \\
\hline
\end{tabular}

\section{A.6 - Mão-de-obra ${ }^{5}$}

\begin{tabular}{lrrrrrr}
\hline \multicolumn{1}{c}{$N^{\circ}$ de postos de trabalho } & S.U.M. & 2000 & 2001 & 2002 & 2003 & 2004 \\
\hline Pessoal dirigente & 400 & 3 & 3 & 4 & 4 & 4 \\
Pessoal técnico & 200 & 4 & 4 & 4 & 4 & 4 \\
P. produção qualificado & 120 & 8 & 8 & 8 & 8 & 8 \\
P. produção não qualificado & 80 & 14 & 17 & 20 & 20 & 20 \\
Pessoal administrativo & 120 & 4 & 4 & 4 & 4 & 4 \\
Pessoal de vendas & 160 & 4 & 4 & 4 & 4 & 4 \\
Pessoal indiferenciado & 80 & 2 & 2 & 2 & 2 & 2 \\
\hline \multicolumn{1}{c}{ TOTAL } & & 39 & 42 & 46 & 46 & 46 \\
\hline [S.U.M.= Salário unitário mensal em contos] & 2000 & 2001 & 2002 & 2003 & 2004 \\
\hline \multicolumn{1}{c}{ Despesas com pessoal (contos) } & & 75040 & 78400 & 87360 & 87360 & 87360 \\
\hline Remunerações & 18010 & 18816 & 20966 & 20966 & 20966 \\
Encargos sociais & 10000 & 10000 & 10000 & 10000 & 10000 \\
\hline Outras despesas com pessoal & 103050 & 107216 & 118326 & 118326 & 118326 \\
\hline \multicolumn{1}{c}{ TOTAL } & & & & &
\end{tabular}


A.7 - Fundo de maneio (contos)

\begin{tabular}{lrrrrrrr}
\hline & Ano & 2000 & 2001 & 2002 & 2003 & 2004 \\
\hline Clientes & 873912 & 1262318 & 1585989 & 1618356 & 1618356 \\
Existências & 1883100 & 2510800 & 3138500 & 3138500 & 3138500 \\
\multicolumn{1}{c}{ Matérias primas } & 1292400 & 1723200 & 2154000 & 2154000 & 2154000 \\
\multicolumn{1}{c}{ Produtos acabados } & 590700 & 787600 & 984500 & 984500 & 984500 \\
\multicolumn{1}{c}{ Subtotal } & 2757012 & 3773118 & 4724489 & 4756856 & 4756856 \\
\hline Fornecedores & 920614 & 1015036 & 1251090 & 1180274 & 1180274 \\
Fornecimentos e serviços terceiros & 159900 & 213200 & 266500 & 266500 & 266500 \\
\multicolumn{1}{c}{ Subtotal } & 1080514 & 1228236 & 1517590 & 1446774 & 1446774 \\
\hline Necessidades fundo de maneio & 1676499 & 2544882 & 3206899 & 3310082 & 3310082 \\
\hline Variação das nec. fundo de maneio & 1676499 & 868384 & 662016 & 103184 & 0 \\
\hline
\end{tabular}

Necessidade de fundo de maneio $=3148045$ contos

\section{A.8 - Custo global do investimento (contos)}

\begin{tabular}{|c|c|c|c|}
\hline \multicolumn{2}{|l|}{ IMOBILIZADO CORPÓREO } & \multicolumn{2}{|l|}{ IMOBILIZADO INCORPÓREO } \\
\hline Terrenos e recursos naturais & 100000 & Estudos e projectos & 20000 \\
\hline Instalações & 80000 & Formação profissional & 15000 \\
\hline Edificios e outras construçōes & 150000 & Software & 10000 \\
\hline Equipamento básico & 827158 & TOTAL & 45000 \\
\hline Equipamento de transporte & 120000 & & \\
\hline Ferramentas e utensílios & 10000 & NECESS. FUNDO DE MANEIO & 3148045 \\
\hline Equipamento administrativo & 25000 & & \\
\hline Imprevistos & 50000 & & \\
\hline TOTAL & 1362158 & TOTAL DE INVESTIMENTO & 4555203 \\
\hline
\end{tabular}




\section{A.9 - Despesas financeiras de financiamento 6}

Empréstimo bancário.. 4555203 contos Prazo de carência ......2 semestres Prazo de reembolso..... 10 semestres Taxa de juro semestral .........3.5\% Mapa da dívida (contos)

\begin{tabular}{rrrrrr}
\hline Ano & Semestre & \multicolumn{2}{c}{$\begin{array}{c}\text { Capital em dívida } \\
\text { Início semestre }\end{array}$} & Juros semestrais & $\begin{array}{c}\text { Amortização de } \\
\text { capital }\end{array}$ \\
\hline \multirow{2}{*}{2000} & Sem.1 & 4555203 & 159432 & 0 & 4555203 \\
& Sem.2 & 4555203 & 159432 & 0 & 4555203 \\
2001 & Sem.1 & 4555203 & 159432 & 569400 & 3985802 \\
& Sem.2 & 3985802 & 139503 & 569400 & 3416402 \\
2002 & Sem.1 & 3416402 & 119574 & 569400 & 2847002 \\
& Sem.2 & 2847002 & 99645 & 569400 & 2277601 \\
2003 & Sem.1 & 2277601 & 79716 & 569400 & 1708201 \\
& Sem.2 & 1708201 & 59787 & 569400 & 1138801 \\
\multirow{2}{*}{2004} & Sem.1 & 1138801 & 39858 & 569400 & 569400 \\
& Sem.2 & 569400 & 19929 & 569400 & 0 \\
\hline
\end{tabular}

A.10 - Despesas financeiras, amortização de capital, outras despesas e impostos indirectos (contos)

\begin{tabular}{lrrrrrr}
\hline & Ano & 2000 & 2001 & 2002 & 2003 & 2004 \\
\hline Despesas financeiras financiamento & 318864 & 298935 & 219219 & 139503 & 59787 \\
Amortização do empréstimo bancário $^{11}$ & 0 & 1138801 & 1138801 & 1138801 & 1138801 \\
Outras despesas e encargos $^{11}$ & 53163 & 76791 & 96481 & 98450 & 98450 \\
Impostos indirectos $^{12}$ & 265815 & 383955 & 482405 & 492250 & 492250 \\
\hline
\end{tabular}

A.11 - Amortizações e reintegrações (contos)

\begin{tabular}{lrrrrrrr}
\hline & Taxa & V.Aquisição & 2000 & 2001 & 2002 & 2003 & 2004 \\
\hline IMOBILIZ. CORPÓREO: & & & & & & & \\
Infraestruturas & $4 \%$ & 80000 & 1600 & 3200 & 3200 & 3200 & 3200 \\
Edifícios e construções & $4 \%$ & 150000 & 3000 & 6000 & 6000 & 6000 & 6000 \\
Equipamentos básicos & $25 \%$ & 827158 & 103395 & 206790 & 206790 & 206790 & 103395 \\
Ferramentas e utensílios & $0 \%$ & 10000 & 0 & 0 & 0 & 0 & 0 \\
Equipamento transporte & $20 \%$ & 120000 & 12000 & 24000 & 24000 & 24000 & 24000 \\
Equipam. Administrativo & $49 \%$ & 25000 & 6125 & 12250 & 6625 & 0 & 0 \\
\hline IMOBIL. INCORPÓREO: & $33.33 \%$ & 45000 & 7499 & 14999 & 14999 & 7504 & 0 \\
\hline \multicolumn{1}{c}{ TOTAL } & & & 133619 & 267238 & 261613 & 247493 & 136595 \\
\hline
\end{tabular}


A.12 - Provisões para depreciação de existências (contos) ${ }^{9}$

\begin{tabular}{lrrrrrr}
\hline & Ano & 2000 & 2001 & 2002 & 2003 & 2004 \\
\hline Saldo inicial da provisão & 0 & 94155 & 125540 & 156925 & 156925 \\
Saldo final da provisão & 94155 & 125540 & 156925 & 156925 & 156925 \\
\hline \multicolumn{1}{c}{ TOTAL } & 94155 & 31385 & 31385 & 0 & 0 \\
\hline
\end{tabular}

\section{A.13 - Conta de exploração previsional (contos)}

\begin{tabular}{lrrrrrr}
\hline & Ano & 2000 & 2001 & 2002 & 2003 & 2004 \\
\hline Vendas líquidas & 5316300 & 7679100 & 9648100 & 9845000 & 9845000 \\
Variação da Produção & 590700 & 196900 & 196900 & 0 & 0 \\
\hline \multicolumn{1}{c}{ TOTAL DOS PROVEITOS } & 5907000 & 7876000 & 9845000 & 9845000 & 9845000 \\
\hline Custo matérias consumidas & 4308000 & 5744000 & 7180000 & 7180000 & 7180000 \\
Energia e combustíveis & 72000 & 96000 & 120000 & 120000 & 120000 \\
Outros fornec. e serviços terceiros & 87900 & 117200 & 146500 & 146500 & 146500 \\
Impostos & 265815 & 383955 & 482405 & 492250 & 492250 \\
Despesas com pessoal & 103050 & 107216 & 118326 & 118326 & 118326 \\
Outras despesas e encargos & 53163 & 76791 & 96481 & 98450 & 98450 \\
Amortizaçōes & 133619 & 267238 & 261613 & 247493 & 136595 \\
Provisões & 102150 & 34050 & 34050 & 0 & 0 \\
\hline \multicolumn{1}{c}{ TOTAL DOS CUSTOS } & 4957802 & 6610585 & 8170210 & 8136520 & 8025621 \\
\hline RESULTADOS CORRENTES & 949198 & 1265415 & 1674790 & 1708480 & 1819379 \\
\hline Encargos financeiros financiamento & 318864 & 298935 & 291219 & 139503 & 59787 \\
\hline RESULTADOS ANTES IMPOSTOS & 630334 & 966480 & 1455570 & 1568977 & 1759592 \\
\hline Provisão para imposto sobre lucro & 252134 & 386592 & 582228 & 627591 & 703837 \\
\hline RESULTADOS LíQUIDOS & 378201 & 579888 & 873342 & 941386 & 1055755 \\
\hline & & & & &
\end{tabular}


A.14 - Orçamento de tesouraria previsional (contos)

\begin{tabular}{lrrrrrr}
\hline & Ano & 2000 & 2001 & 2002 & 2003 & 2004 \\
\hline RECEBIM. EXPLORAÇÃO (vendas) & 4442388 & 7290695 & 9324429 & 9812633 & 9845000 \\
\hline Matérias primas e subsidiárias & 4679786 & 6080378 & 7374745 & 7250816 & 7180000 \\
Despesas com pessoal & 103050 & 107216 & 118326 & 118326 & 118326 \\
Outras despesas e encargos & 53163 & 76791 & 96481 & 98450 & 98450 \\
Impostos indirectos & 265815 & 383955 & 482405 & 492250 & 492250 \\
Impostos sobre lucros & 0 & 252134 & 386592 & 582228 & 627591 \\
\hline PAGAMENTOS EXPLORAÇÃO & 5101814 & 6900474 & 8458550 & 8542071 & 8516617 \\
\hline \multicolumn{1}{c}{ SALDO DE EXPLORAÇÃO } & -659426 & 390221 & 865879 & 1270562 & 1328383 \\
\hline RECEBIMENTOS DE CAPITAL & 4555203 & & & & \\
\hline Capital fixo & 1407158 & & 1138801 & 1138801 & 1138801 & 1138801 \\
Reembolso empréstimo bancário & & & & & & \\
Encargos financeiros financiamento & 318864 & 298935 & 291219 & 139503 & 59787 \\
\hline TOTAL PAGAMENTOS CAPITAL & 1726022 & 1437736 & 1358020 & 1278304 & 1198588 \\
\hline SALDO DE CAPITAL & 2829180 & -1437736 & -1358020 & -1278304 & -1198588 \\
\hline Saldo de exploração + saldo capital & 2169754 & -1047515 & -492141 & -7742 & 129795 \\
\hline
\end{tabular}

\section{A.15 -Balanços previsionais (contos)}

\begin{tabular}{|c|c|c|c|c|c|}
\hline Ano & 2000 & 2001 & 2002 & 2003 & 2004 \\
\hline \multicolumn{6}{|l|}{ ACTIVO } \\
\hline Disponivel & 2169754 & 1122239 & 630099 & 622357 & 752152 \\
\hline Clientes & 873912 & 1262318 & 1585989 & 1618356 & 1618356 \\
\hline \multicolumn{6}{|l|}{ Existências } \\
\hline - Matérias-primas & 1292400 & 1723200 & 2154000 & 2154000 & 2154000 \\
\hline - Produtos acabados & 590700 & 787600 & 984500 & 984500 & 984500 \\
\hline Provisão para depreciação existências & 94155 & 125540 & 156925 & 156925 & 156925 \\
\hline CAPITAL CIRCULANTE & 4832612 & 4769817 & 5197663 & 5222288 & 5352083 \\
\hline Imobilizado bruto & 1407158 & 1407158 & 1407158 & 1407158 & 1407158 \\
\hline Corpóreo & 1362158 & 1362158 & 1362158 & 1362158 & 1362158 \\
\hline Incorpóreo & 45000 & 45000 & 45000 & 45000 & 45000 \\
\hline (-)Amortizaçōes acumuladas & 133619 & 400857 & 662470 & 909963 & 1046558 \\
\hline Imobilizado líquido & 1273539 & 1006301 & 744688 & 497195 & 360600 \\
\hline TOTAL DO ACTIVO & 6106151 & 5776118 & 5942351 & 5719483 & 5712683 \\
\hline
\end{tabular}




\begin{tabular}{|c|c|c|c|c|c|}
\hline \multicolumn{6}{|l|}{ PASSIVO } \\
\hline \multicolumn{6}{|l|}{ Exígivel a curto prazo } \\
\hline Fornecedores & 920614 & 1015036 & 1251090 & 1180274 & 1180274 \\
\hline Empréstimos bancários & 1138801 & 1138801 & 1138801 & 1138801 & 0 \\
\hline Provisāo para imposto sobre lucro & 252134 & 386592 & 582228 & 627591 & 703837 \\
\hline \multicolumn{6}{|l|}{ Exigível a médio/longo prazo } \\
\hline Emprestimo bancário & 3416402 & 2277601 & 1138801 & 0 & 0 \\
\hline TOTAL DO PASSIVO & 5727950 & 4818030 & 4110920 & 2946666 & 1884111 \\
\hline \multicolumn{6}{|l|}{ CAPITAIS PRÓPRIOS } \\
\hline Reservas e resultados transitados & 0 & 378201 & 958088 & 1831431 & 2772817 \\
\hline Resultados líquidos & 378201 & 579888 & 873342 & 941386 & 1055755 \\
\hline TOTAL CAPITAL PRÓPRIO & 378201 & 958088 & 1831431 & 2772817 & 3828572 \\
\hline PASSIVO + CAPITAL PRÓPRIO & 6106151 & 5776118 & 5942351 & 5719483 & 5712683 \\
\hline
\end{tabular}

\section{A.16 - Mapa de origens e aplicações de fundos (contos)}

\begin{tabular}{lrrrrrr}
\hline & Ano & 2000 & 2001 & 2002 & 2003 & 2004 \\
\hline $\begin{array}{l}\text { CAPITAIS PRÓPRIOS: } \\
\text { Autofinanciamento }\end{array}$ & 511820 & 847126 & 1134955 & 1188880 & 1192350 \\
\hline CAPITAIS ALHEIOS & & & & & \\
Médio e longo prazo: Emprést. Banc. & 4555203 & & & & & \\
Curto prazo & & & & & & \\
Crédito de fornecedores & 920641 & 94422 & 236055 & -70816 & 0 \\
Outros (provisões p/ imp. s/ lucro) & 252134 & 134458 & 195636 & 45363 & 76246 \\
$\quad$ TOTAL DAS ORIGENS & 6239770 & 1076006 & 1566646 & 1163426 & 1268596 \\
\hline Investimento em capital fixo & 1407158 & & & & \\
Investimento capital circulante & 4832612 & -62795 & 427846 & 24625 & 129795 \\
Reembolso empréstimo bancário & & 1138801 & 1138801 & 1138801 & 1138801 \\
$\quad$ TOTAL DAS APLICAÇÕES & 6239770 & 1076006 & 1566646 & 1163426 & 1268596 \\
\hline
\end{tabular}


A.17 - Meios libertos (contos)

\begin{tabular}{lrrrrrr}
\hline & Ano & 2000 & 2001 & 2002 & 2003 & 2004 \\
\hline Resultados líquidos & 378201 & 579888 & 873342 & 941386 & 1055755 \\
Amortizações e reintegrações & 133619 & 267238 & 261613 & 247493 & 136595 \\
Provisões & 94155 & 31385 & 31385 & 0 & 0 \\
Encargos financeiros financiamento & 318864 & 298935 & 219219 & 139503 & 59787 \\
Provisão para imposto sobre lucro & 252134 & 386592 & 582228 & 627591 & 703837 \\
\hline \multicolumn{1}{c}{ TOTAL DE MEIOS LIBERTOS } & 1179972 & 1564038 & 1967788 & 1955974 & 1955974 \\
\hline O custo global do investimento é de 4.555.203 contos, com um período de \\
recuperação de 3 anos.
\end{tabular}

A.18 - Valor actualizado líquido (contos)

\begin{tabular}{lrrrrrr}
\hline & Ano & 2000 & 2001 & 2002 & 2003 & 2004 \\
\hline Investimento & -4555203 & & & & \\
Meios libertos & 1179972 & 1564038 & 1967788 & 1955974 & 1955974 \\
Valor residual em 1998 & & & & & 360600 \\
\hline
\end{tabular}

Taxa Interna Rentabilidade $=\mathbf{2 4 . 3} \%$

A.19 - Valor acrescentado bruto - VAB (contos)

\begin{tabular}{lrrrrrr}
\hline & Ano & 2000 & 2001 & 2002 & 2003 & 2004 \\
\hline Resultados líquidos & 378201 & 579888 & 873342 & 941386 & 1055755 \\
Provisão para imposto sobre lucro & 252134 & 386592 & 582228 & 627591 & 703837 \\
Despesas com pessoal & 103050 & 107216 & 118326 & 118326 & 118326 \\
Encargos financeiros & 318864 & 298935 & 219219 & 139503 & 59787 \\
Amortizações e reintegrações & 133619 & 267238 & 261613 & 247493 & 136595 \\
Provisões & 94155 & 31385 & 31385 & 0 & 0 \\
\hline \multicolumn{1}{c}{ TOTAL (VAB) } & 1280022 & 1671254 & 2086114 & 2074300 & 2074300 \\
\hline
\end{tabular}




\section{A.20 - Análise de sensibilidade}

Hipótese 1 -Diminuição dos proveitos em 10\%, mantendo os custos constantes

Conta de exploração (contos)

\begin{tabular}{lrrrrrr}
\hline & Ano & 2000 & 2001 & 2002 & 2003 & 2004 \\
\hline Proveitos & 5316300 & 7088400 & 8860500 & 8860500 & 8860500 \\
Custos & 4957802 & 6610585 & 8170210 & 8136520 & 8025621 \\
Resultados correntes & 358498 & 477815 & 690290 & 723980 & 834879 \\
Encargos financeiros & 318864 & 298935 & 219219 & 139503 & 9787 \\
Resultados antes imposto & 39634 & 178880 & 471070 & 584477 & 775092 \\
Provisão para imposto sobre lucro & 15854 & 71552 & 188428 & 233791 & 310037 \\
Resultados líquidos & 23781 & 107328 & 282642 & 350686 & 465055 \\
\hline
\end{tabular}

Valor actualizado líquido (contos)

\begin{tabular}{|c|c|c|c|c|c|c|}
\hline & Ano & 2000 & 2001 & 2002 & 2003 & 2004 \\
\hline Investimento & & -4555203 & & & & \\
\hline Meios libertos & & 586272 & 776438 & 983288 & 971474 & 971474 \\
\hline Valor residual & & & & & & 360600 \\
\hline
\end{tabular}

Taxa Interna Rentabilidade $=\mathbf{- 1 . 7 \%}$

Hipótese 2 - Aumento dos custos em 10\%, mantendo os proveitos constantes Conta de exploraçao (contos)

\begin{tabular}{|c|c|c|c|c|c|}
\hline Ano & 2000 & 2001 & 2002 & 2003 & 2004 \\
\hline Proveitos & 5907000 & 7876000 & 9845000 & 9845000 & 9845000 \\
\hline Custos & 5453582 & 7271644 & 8987231 & 8950172 & 8828183 \\
\hline Resultados correntes & 453418 & 604357 & 857769 & 894828 & 1016817 \\
\hline Encargos financeiros & 318864 & 298935 & 219219 & 139503 & 59787 \\
\hline Resultados antes imposto & 134554 & 305421 & 638549 & 755325 & 957030 \\
\hline Provisão para imposto sobre lucro & 53822 & 122169 & 255420 & 302130 & 382812 \\
\hline Resultados líquidos & 80732 & 183253 & 383130 & 453195 & 574218 \\
\hline
\end{tabular}

Valor actualizado líquido (contos)

\begin{tabular}{lrrrrrr}
\hline & Ano & 2000 & 2001 & 2002 & 2003 & 2004 \\
\hline Investimento & -4555203 & & & & \\
Meios libertos & 681192 & 902980 & 1150767 & 1142322 & 1153411 \\
Valor residual & & & & & 360600 \\
\hline
\end{tabular}

Taxa Interna Rentabilidade $=\mathbf{5 . 1 \%}$ 
A.21 - Produtividade

\begin{tabular}{lrrrrrr}
\hline & Ano & 2000 & 2001 & 2002 & 2003 & 2004 \\
\hline VAB (contos) & 1280022 & 1671254 & 2086114 & 2074300 & 2074300 \\
Volume de emprego & 39 & 42 & 46 & 46 & 46 \\
VAB per capita & 32821 & 39792 & 45350 & 45093 & 45093 \\
\hline
\end{tabular}

\section{A.22 - Indicadores financeiros}

\begin{tabular}{lrrrrrr}
\hline & Ano & 2000 & 2001 & 2002 & 2003 & 2004 \\
\hline Activo circulante & 4832612 & 4769817 & 5197663 & 5222288 & 5352083 \\
Exígivel a curto prazo & 2311548 & 2540428 & 2972119 & 2946666 & 1884111 \\
Liquidez geral & 2,1 & 1,9 & 1,7 & 1,8 & 2,8 \\
Capitais próprios & 378201 & 958088 & 1831431 & 2772817 & 3828572 \\
Activo total & 6106151 & 5776118 & 5942351 & 5719483 & 5712683 \\
Autonomia financeira & 0,1 & 0,2 & 0,3 & 0,5 & 0,7 \\
Capitais próprios & 378201 & 958088 & 1831431 & 2772817 & 3828572 \\
Passivo & 5727950 & 4818030 & 4110920 & 2946666 & 1884111 \\
Solvabilidade & 0,1 & 0,2 & 0,4 & 0,9 & 2,0 \\
Fundo de maneio & 2521064 & 2229389 & 2225543 & 2275622 & 3467972 \\
Tesouraria & 844565 & -315493 & -981355 & -1034460 & 157890 \\
\hline
\end{tabular}

\section{NOTAS DOS ANEXOS}

1 Considerando um prazo médio do "stock" do produto de 30 dias.

2 Considerando um prazo médio de recebimentos de 60 dias.

3 Considera-se um prazo médio de "stock" de matérias primas de 90 dias, uma vez que a produção é sazonal, sendo necessário acumular "stocks" para assegurar a transformação em contínuo. O prazo médio de pagamentos é de 60 dias.

${ }^{4}$ Os valores dos fornecimentos e' serviços de terceiros são calculados empiricamente ou estimados.

5 As despesas de mão-de-obra são remuneradas de acordo com valores considerados médios para o mercado de trabalho nacional.

6 Para efeitos destes cálculos, o financiamento é feito, recorrendo na totalidade a capitais alheios, através de um empréstimo bancário, embora se reconheça a dificuldade, na prática usual, do financiamento total do projecto por parte de terceiros.

${ }_{8}^{7}$ Para outras despesas e encargos assumiu-se um valor de $1 \%$ das vendas anuais.

${ }^{8}$ Para impostos indirectos utilizou-se um valor calculado a partir de $5 \%$ das vendas anuais.

${ }^{9}$ É considerada uma percentagem de 5\% para depreciação de existências. 


\section{BIBLIOGRAFIA}

BÖHM, F., HEINISCH, R., PETER, S., WEIDNER, E. (1989), Supercritical Fluids Science and Tecnology, Ed. Johnston \& Penninger, "American Chemical Society Symposium Series" 406, American Chemical Society.

BARROS, C. (1994), Decisóes de Investimento e Financiamento de Projectos, $3^{\mathrm{a}} \mathrm{Ed} ., \mathrm{Ed}$. Sílabo, Lisboa.

BIERMAN, H., SMIDT, S. (1993), The Capital Budgeting Decision - Economic Analysis of Investiment Projects, $8^{\text {th }}$ Ed., Macmillan Publishing Company, New York.

BRAVO, J. L., ROCHA, J. A., FAIR, J. R. (1985), Hydrocarbon Process, 64(1), pp. 9195

BRUNETTI, L., DAGHETTA, A, FEDELI, E., KIKIC, I., ZANDERIGHI, L. (1989), Journal of American Oil Chemical Society, 66, p. 209.

CARMELO, P. J. (1995), Tranferência de Massa em Fluidos Supercríticos: Resultados Experimentais e Modelação, Tese de doutoramento, Universidade Nova de Lisboa, Lisboa.

COENEN, H.; KRIEGEL, E. (1978), Patente Alemã DOS 2843 920, F. Krupp GmbH, Essen.

CONSELHO OLEÍCOLA INTERNACIONAL - COI (1984), "O património das oliveiras e a sua importância sócio-económica mundial", Olivae, 2 (6), pp. 18-19.

COI (1985), "Normalização dos b́leos de azeitona", Olivae, 8 (9), pp 9-14.

COSTA, J. Almeida; MELO, A. Sampaio (1992), Dicionário da Língua Portuguesa, $6^{\mathrm{a}}$ Ed., Porto Editora.

COULSON, J. M., RICHARDSON, J. F. (1983), Chemical Engineering, Volume 6: Design, Pergamon Press, Oxford.

CYGNAROWICZ, M. L., SEIDER, W. D. (1990), Biotecnology Progress, 6, pp. 82-91.

DE HAAN, A. B.; DE GRAAUW, J. (1991), Industrial Engineering Chemical Research, 30, pp. 2463-2470.

FERNANDEZ, M. Cruz (1983), Fábricas de aceite en el campo hispano-romano, II Congresso Internacional da Produção e Comércio de Azeite na Antiguidade, Ed. Universidade Complutense de Madrid, pp. 561-599, Madrid, Espanha.

HUBERT, P., VITZHUM, O.G. (1978), Angew. Chem. Int. Ed. Engl., 17, p. 710.

INSTITUTO NACIONAL DE ESTATÍSTICA - INE, Estatisticas Agrícolas (1993, 1994, 1995 e 1996), INE, Lisboa.

INSTITUTO PORTUGUÊS DA QUALIDADE - IPQ (1972), Norma Portuguesa de Gorduras e Oleos Comestiveis, Ed. IPQ.

JOHNSTON, K. P.; PENNINGER, M. L. (1989), Supercritical Fluids Science and Technology, ACS Symposium Series 406, American Chemical Society, pp. 478498. 
JORNAL OFICIAL DA COMUNIDADE EUROPEIA (11-7-1991), Regulação n. 2568/91.

MARTÍ, J. Tous; AROCA, A. Romero (1993), Variedades de Olivo, Ed. Fundación "la Caixa", Barcelona, Espanha.

NUNES DA PONTE, M.; SIMÕES, P.; GONÇALVES, M.; CARMELO, P.; PEREIRA, P. J.; GOMES DE AZEVEDO, E.; MATOS, H. A. (1992), Extracção Supercrítica de óleos vegetais, monografia submitida ao Prémio da Boa Esperança de 1992 de Ciência e Tecnologia, à qual foi atribuída uma Menção Honrosa.

PENNINGER, J. L.; RADOSZ, M.; MCHUGH, M. A.; KRUKONIS, V. J. (1985), Supercritical Fluid Technology, Ed. Elsevier, Amsterdam, pp. 265-280.

PEREIRA, P. J. A. (1995), Equilíbrio de Fases em Fluidos Supercríticos: Resultados Experimentais e Modelação, Tese de doutoramento, Universidade Nova de Lisboa, Lisboa.

PETERS, M. S., TIMMERHAUS, K. D. (1980), Plant Design and Economics for Chemical Engineers, $3^{\text {rd }}$ Ed., McGraw-Hill, New York.

ROSS, S. A., WESTERFIELD, R. W., JAFFE, J. F. (1996), Corporate Finance, $4^{\text {th }}$ Ed., Ed. Irwin, Chicago, E.U.A.

SADA, José Luis Ortega (1993), Manual de explotaciones agrícolas, Ed. Mundi-Prensa, Madrid, Espanha.

SCHNEIDER, G. M.; STAHL, E.; WILKE, G. (1980), Extraction with Supercritical Gases, Ed. Verlag Chemie, Weinheim, Alemanha.

SULZER BROTHERS LTD. (1991), Separation Columns for Distillation and Absorption, Information Bulletin

ZOZEL, K. (1973), Patente Alemã DAS 2332 038, Studiengesellschsaft Kohle mbH, Mulheim. 